\title{
Disease Incidence in Sugar Beet Fields Is Correlated with Microbial Diversity and Distinct Biological Markers
}

\author{
Peter Kusstatscher, ${ }^{1,2}$ Tomislav Cernava, ${ }^{2,3}$ Karsten Harms, ${ }^{4}$ Johann Maier, ${ }^{4}$ Herbert Eigner, ${ }^{5}$ Gabriele \\ Berg, $^{2}$ and Christin Zachow ${ }^{1, \dagger}$ \\ ${ }^{1}$ Austrian Centre of Industrial Biotechnology, Petersgasse 14, 8010 Graz, Austria \\ ${ }^{2}$ Institute of Environmental Biotechnology, Petersgasse 12, $8010 \mathrm{Graz}$, Austria \\ ${ }^{3}$ Roombiotic GmbH, c/o: SciencePark, Stremayrgasse 16/IV, 8010 Graz, Austria \\ ${ }^{4}$ Südzucker AG, Maximilianstraße 10, 68165 Mannheim, Germany \\ ${ }^{5}$ Agrana Research \& Innovation Center, Josef-Reither-Straße 21-23, 3430 Tulln, Austria
}

Accepted for publication 28 February 2019.

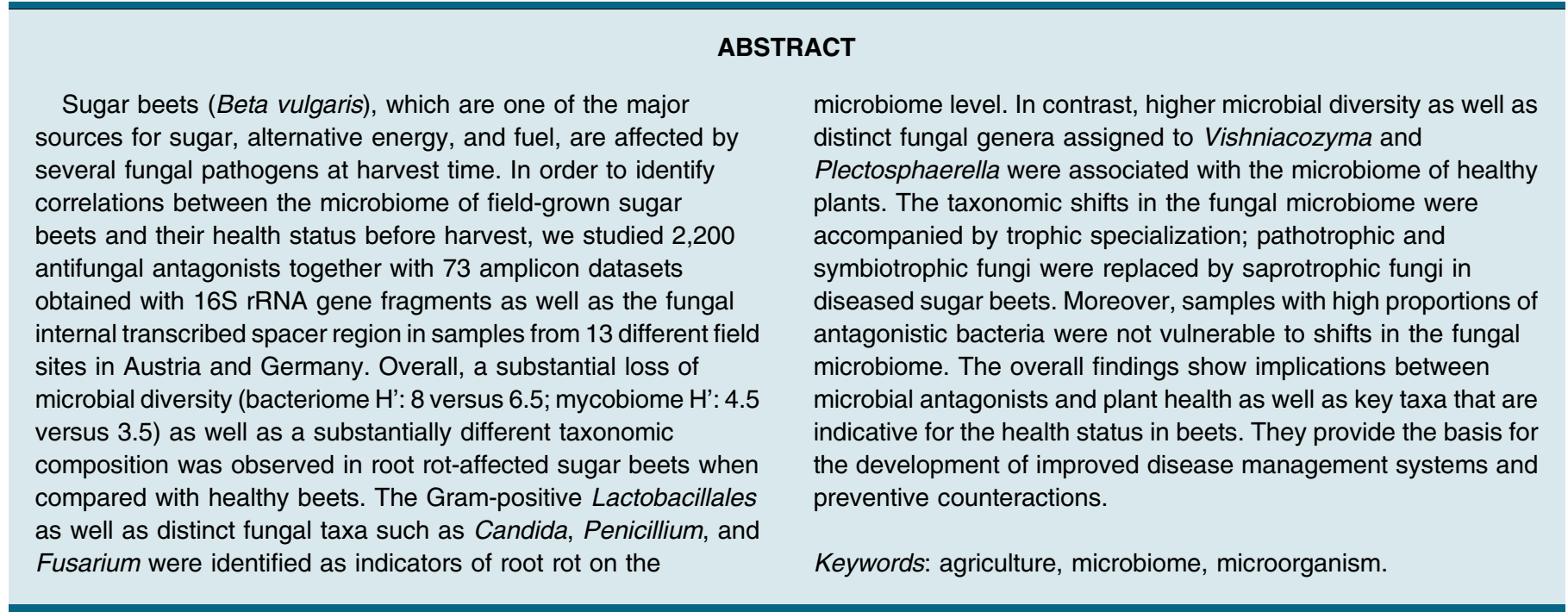

Plants live in close relationships with their microbiota and are thus often considered as holobionts (Berg et al. 2016; Vandenkoornhuyse et al. 2015). They offer different colonization niches for microorganisms

\section{†Corresponding author: C. Zachow; christinzachow@acib.at}

Funding: This work was supported by the Federal Ministry of Science, Research and Economy (BMWFW), the Federal Ministry of Traffic, Innovation and Technology (bmvit), the Styrian Business Promotion Agency SFG, the Standortagentur Tirol, the Government of Lower Austria and ZIT-Technology Agency of the City of Vienna through the COMET-Funding Program managed by the Austrian Research Promotion Agency FFG (grant number 282482).

*The $\boldsymbol{e}$-Xtra logo stands for "electronic extra" and indicates that two supplementary figures and two supplementary tables are published online.

The author(s) declare no conflict of interest.

(C) 2019 The American Phytopathological Society that establish mutualistic, neutral, or parasitic interaction with the plant (Compant et al. 2010; Raaijmakers et al. 2009). These associations were formed as early as during the Devonian and are evidenced by fossil records (Krings et al. 2012). In these coevolved symbioses, microbes colonizing the plant rhizo- and endosphere are plant-specific (Berg and Smalla 2009) and can fulfill different roles to support their host's health and productivity (Berg 2009; Lugtenberg et al. 2002). Not only the prevalence of microbial pathogens but especially microbial diversity in general was found to be a key factor for plant health and prevention of pathogen outbreaks (Mendes et al. 2011; van Elsas et al. 2012; Yan et al. 2017). Detailed functional understanding of beneficial, plant-colonizing microorganisms and their modes of action in the large microbial community is crucial for the development of biological applications in agriculture (Berg et al. 2014, 2017).

Sugar beet (Beta vulgaris L.) is a herbaceous dicotyledonous plant, mainly grown for the production of sugar (sucrose content up 
to $18 \%$ ) in temperate regions (Trebbi and McGrath 2004). In the last years, its importance for biotechnological processes and as an alternative energy source has increased (Maung and Gustafson 2011). The seasonal yields in the main growing regions (Northern Europe and North America) are around 55 tons of sugar beets or 8 tons of white sugar per hectare and mainly depend on climatic factors and crop rotation strategy (Götze et al. 2017; Kenter et al. 2006; Pervin and Islam 2015). However, various fungal pathogens can diminish the yearly harvest and cause substantial economic losses at all plant stages. While Aphanomyces cochlioides Drechsler (Drechsler 1928) and Pythium ultimum Trow (Osburn et al. 1989) cause root and seedling rot in an early stage of plant development, Sclerotium rolfsii Sacc., Rhizoctonia solani Kühn (Kiewnick et al. 2001), and Cercospora beticola Sacc. (Weiland and Koch 2014) can cause severe harvest losses during later growth stages (Zachow et al. 2010). After harvest, Fusarium spp., often already present in the mycobiome of the harvested beets, can cause storage rot and lead to potentially high sugar yield losses (Liebe et al. 2016). In order to reduce disease incidence, various chemical fungicides are currently used, while biological treatments only play a minor role (Bartholomäus et al. 2017; Georgakopoulos et al. 2002). Natural antagonists of plant-pathogenic fungi, however, are a promising alternative for plant protection (Berg 2009). The indigenous microbiome of sugar beets and their ancestors was shown to carry microbial antagonists with the potential of averting fungal infection (Zachow et al. 2014, 2008). When grown in fields, individual sugar beets are not equally affected by prevalent pathogens and some remain unaffected even under high pathogen pressure. This varying disease severity on the field most likely results from varying pathogen pressure or protection by beneficial microorganisms present in the rhizosphere of single sugar beet roots (Büttner et al. 2008; Zachow et al. 2014).

While it is already known that plants interact closely with their colonizing microbiota, knowledge related to how whole microbial communities influence plant health is still scarce and requires evaluations at microbial community level (Berendsen et al. 2012). We hypothesized that the health status of the plants will not only depend on the occurrence of specific beneficial species but be reflected by the whole prevalent bacteriome as well as the mycobiome. Therefore, we selected healthy and diseased sugar beets from infected fields in Austria and Germany before harvest and assessed specific signatures in their microbiomes. The antagonistic potential of bacterial isolates, obtained from healthy beets, was analyzed in order to assess differences in the microbial community composition related to the frequency of antagonistic bacteria.

\section{MATERIALS AND METHODS}

Sugar beet sampling and isolation of bacteria. Healthy $(n=46)$ and diseased $(n=27)$ sugar beets were obtained from different fields in Austria (Upper Austria) and Germany (Bavaria). The exact location of the sampling sites is provided in Table 1. Fields were selected for their disease (beet rot) frequency and sampled shortly before harvest. Healthy sugar beets that were surrounded by diseased plants were targeted (Supplementary Fig. S1). In addition, diseased sugar beets from the surrounding areas were sampled and used as comparison in the microbiome study. After arrival in the laboratory within $24 \mathrm{~h}, 20 \mathrm{~g}$ of the healthy sugar beet skin was peeled and washed with $50 \mathrm{ml}$ of sodium chloride solution $(0.85 \%)$ in a stomacher (Bagmixer; Intersciences, St. Nom, France) for 3 min. The obtained solution was used for total community DNA extractions and simultaneously plated in dilutions on nutrient agar (Sifin, Berlin, Germany) after heat treatment $\left(90^{\circ} \mathrm{C}, 30 \mathrm{~min}\right)$ to screen for spore forming bacteria. A total of 2,200 bacterial strains (48 per sugar beet) were picked after 2 days of incubation and preserved in 96 well plate glycerol stocks $\left(30 \%\right.$ glycerol) at $-80^{\circ} \mathrm{C}$. For the diseased sugar beets, $20 \mathrm{~g}$ of peel was washed with $50 \mathrm{ml}$ of sodium chloride solution $(0.85 \%)$ by homogenizing for $3 \mathrm{~min}$. The obtained solution was used for total community DNA extractions.

Antagonistic activity tests against plant pathogens. The bacterial strains from the isolation approach were tested for their antagonistic activity against a saprophytic fungal isolate Fusarium oxysporum 108_10C (strain collection of the Institute of Environmental Biotechnology-Graz University of Technology), previously isolated from diseased sugar beets. The dual culture assays were conducted on Waksman agar ( $\mathrm{pH}$ 6.8) containing sodium chloride at $5 \mathrm{~g} /$ liter (Carl-Roth, Karlsruhe, Germany), pepton at 5 $\mathrm{g} /$ liter (Carl-Roth), glucose at $10 \mathrm{~g} /$ liter (Carl-Roth), yeast extract at $3 \mathrm{~g} /$ liter (Carl-Roth), and agarose at $18 \mathrm{~g} /$ liter (Carl-Roth), as described by Berg et al. (2002). Growth inhibition was documented by measuring the inhibition zone and this was used to determine the antagonistic potential from each field.

TABLE 1

Antagonistic potential of bacteria isolated from different fields ${ }^{a}$

\begin{tabular}{|c|c|c|c|c|c|}
\hline Field & Country & GPS & Samples & Antagonists (\% of isolates) & Number of antagonists \\
\hline Moarfeld & AT & $48.206228,14.625774$ & 5 & 21.25 & 51 \\
\hline Wirtsacker & DE & $48.765223,12.783715$ & 5 & 7.50 & 18 \\
\hline Berg am Spitz & AT & $48.198215,14.627236$ & 3 & 6.94 & 10 \\
\hline Vierhofener Feld & $\mathrm{DE}$ & $48.675090,12.997164$ & 5 & 3.33 & 8 \\
\hline Haidfeld & $\mathrm{DE}$ & $48.818879,12.919264$ & 2 & 3.13 & 3 \\
\hline Rettenbach & $\mathrm{DE}$ & $48.812911,12.887295$ & 6 & 3.13 & 9 \\
\hline Waldweg & $\mathrm{DE}$ & $48.810239,12.906380$ & 5 & 1.67 & 4 \\
\hline Dorffeld & AT & $48.200278,14.624533$ & 2 & 0.00 & 0 \\
\hline
\end{tabular}

a High occurrence of antagonistic isolates ( $>6 \%$ of tested isolates) are indicated in bold. 
DNA extraction and amplicon library construction. A total of $4 \mathrm{ml}$ of homogenate obtained in the initial samples preparations steps (described above) was centrifuged at $13,000 \times g$ for $20 \mathrm{~min}$ at $4^{\circ} \mathrm{C}$. Pellets were stored at $-70^{\circ} \mathrm{C}$ until further use. Total community DNA was extracted from the samples using the FastDNA Kit for Soil (MP Biomedicals, U.S.A.). In the first step, the pellet was resuspended in $978 \mu \mathrm{l}$ of sodium phosphate buffer. All other steps were conducted according to the manufacturer's instructions. The DNA extracts were used for $16 \mathrm{~S}$ rRNA gene and internal transcribed spacer (ITS) amplicon amplifications. The primer pair 515f (GTGYCAGCMGCCGCGGTAA) and 926r (CCGYCAAT TYMTTTRAGTTT) targeting the complete hypervariable region 4 of the 16S rRNA gene and the ITS1 region primer pair ITS1f (CTTGGTCATTTAGAGGAAGTAA) and ITS2 (GCTGCGTTCT TCATCGATGC) were used. Both primer pairs were modified with specific primer pads (TATGGTAATT/AGTCAGCCAG) and linkers $(\mathrm{GT} / \mathrm{GG})$ for the attachment of sample-specific Golay barcode sequences, as described in the protocols and standards section of the Earth microbiome project (Walters et al. 2015).

PCR was conducted in two steps. In the first PCR step, the abovementioned primer pairs were used. In a secondary PCR step, barcode sequences were attached to the modified primer pads and linkers for multiplexing. All PCR reactions were conducted in triplicates. The first PCR (amplification of the V4 region or ITS region) was performed in a total volume of $10 \mu \mathrm{l}$ (1 $\mu$ l of DNA, $2 \mu \mathrm{l}$ of Taq\&Go, $0.1 \mu \mathrm{l}$ of each primer, $0.15 \mu \mathrm{l}$ of mPNA and pPNA, and $6.5 \mu$ l of water). The amplification blockers mPNA and pPNA were added to prevent the amplification of mitochondrial and chloroplast DNA (Lundberg et al. 2013). The reactions were performed on a Whatman Biometra Tpersonal and Tgradient thermocycler (Biometra $\mathrm{GmbH}$, Göttingen, Germany) with the following settings: $95^{\circ} \mathrm{C}$ for $45 \mathrm{~s}, 78^{\circ} \mathrm{C}$ for $5 \mathrm{~s}, 55^{\circ} \mathrm{C}$ for $45 \mathrm{~s}, 72^{\circ} \mathrm{C}$ for $90 \mathrm{~s}(35 \mathrm{x})$, including an initial denaturation of $5 \mathrm{~min}$ at $95^{\circ} \mathrm{C}$ and a final extension of 5 min at $72^{\circ} \mathrm{C}$. In the second PCR (multiplexing with Golay barcodes), a total volume of $30 \mu \mathrm{l}$ ( $2 \mu \mathrm{l}$ of the first PCR [template], $6 \mu \mathrm{l}$ of Taq\&Go, $1.2 \mu \mathrm{l}$ of barcode-primers, and $19.6 \mu \mathrm{l}$ of water) was run at the following settings: $95^{\circ} \mathrm{C}$ for $30 \mathrm{~s}, 53^{\circ} \mathrm{C}$ for $30 \mathrm{~s}, 72^{\circ} \mathrm{C}$ for $30 \mathrm{~s}(15 \times)$, including an initial denaturation of $5 \mathrm{~min}$ at $95^{\circ} \mathrm{C}$ and a final extension of $5 \mathrm{~min}$ at $72^{\circ} \mathrm{C}$. After each PCR amplification step, the quality was checked by gel electrophoresis. All three technical replicates of quality checked PCRs from each sample were pooled and purified using the Wizard SV Gel and PCR Clean-Up System (Promega, Madison, WI, U.S.A.) according to the manufacturer's protocol. Equimolar DNA concentrations of each barcoded amplicon sample were sent to GATC Biotech AG, Konstanz, Germany. After entry quality control and adapter ligation, 16S rRNA gene fragment and ITS region amplicons were sequenced on an Illumina HiSeq instrument with paired-end sequencing $(2 \times 300 \mathrm{bp})$.

Initial bioinformatic data analysis within the QIIME pipeline. Paired-end amplicon sequences obtained on the Illumina HiSeq platform were analyzed in a combined approach with QIIME 2 (2018.6 release) and QIIME 1.9.1 (Caporaso et al. 2010) (Supplementary Table S1). After joining reads and barcode extraction in QIIME 1.9.1, the data were transferred to QIIME 2. The data were demultiplexed and the DADA2 algorithm (Callahan et al. 2016) was applied to denoise truncated reads and to generate sequence variants (SVs), which were then summarized in a feature table. To increase the quality chimeric data as well as mitochondria and chloroplast reads (for $16 \mathrm{~S}$ data) or bacteria and archaea reads (for ITS data) were excluded from the dataset by filtering. A total of 6,619,417 ITS and $1,762,91316 \mathrm{~S}$ reads were assigned to 3,233 and 9,480 SVs, respectively (Supplementary Table S2). Alpha and beta diversity analysis were performed using the QIIME 2 core diversity metrics and group significance tests. The dataset was rarefied to a depth of 2,400 reads (16S data) and 11,000 reads (ITS data) and rarefaction analysis indicated this was sufficient sequencing depth to capture the species diversity in all samples (Supplementary Fig. S2). For taxonomic assignment, a Naïve-Bayes classifier was trained on the SILVA v123 (Quast et al. 2013) at 99\% similarity as well as the UNITE v7 database (Kõljalg et al. 2013). The confidence threshold for feature classification was set to the default value of 0.7 .

Bioinformatic comparison of different sample groups. Feature tables were split into three groups according to their health status (high, low, and diseased) and each group filtered for the core microbiome (features present in $50 \%$ of the samples), which revealed in total 223 bacterial and 243 fungal core features. After remerging, the respective core microbiomes networks based on the identified SVs were generated within QIIME 1.9.1. with the 'make_OTU_network' script using collapsed feature tables generated in QIIME 2 and further visualized in Cytoscape 3.6.1 (Shannon et al. 2003). Significant taxonomic differences between the groups were observed with the ANCOM test in QIIME 2. Venn diagrams were calculated with a web tool (http://bioinformatics. psb.ugent.be/webtools/Venn/). Functional analysis of fungal feature tables was performed using the FUNGuild online tool (http:// www.stbates.org/guilds/app.php).

Statistical analysis of bioinformatics data. Alpha and beta diversity were analyzed within the QIIME 2 pipeline. In order to assess their significance, the implemented Kruskal-Wallis (alpha diversity) and the anosim test (beta diversity) were used. Significant taxonomic differences between the groups were assessed with the ANCOM test in QIIME 2.

Deposition of sequence data. Raw data for each sample used in this study was deposited at the European Nucleotide Archive (ENA; https://www.ebi.ac.uk/ena) in the fasta-file format and is available under the Bioproject accession number PRJEB28861.

\section{RESULTS}

Antagonistic potential on different sugar beet fields. In order to screen for bacterial antagonists against the fungal pathogen Fusarium oxysporum, bacteria were sampled from 13 fields in Austria and Germany. The antagonistic potential was evaluated with dual culture assays conducted with 2,200 bacterial strains obtained from healthy sugar beets within highly infected sugar beet fields (Table 1). A total of 257 bacterial antagonists, which occurred in distinct fields (Dierneder Staffling [118], Moarfeld [51], Gilsenöd-Blindmühl [33], Wirtsacker [18], and Berg am Spitz [10]), showed a high antagonistic potential, while there were no or lower proportions of antagonistic bacteria in other fields (Table 1).

Microbial diversity is significantly decreased in diseased sugar beets. Amplicon data obtained from 73 samples revealed 223 bacterial and 243 fungal core operational taxonomic units (OTUs). The comparison of healthy and diseased sugar beets showed overall a lower microbial diversity (alpha diversity) in diseased samples (Shannon index: 6.5 in 16S samples and 3.5 in ITS samples) compared with the microbiome of healthy sugar beets (Shannon index: 8.0 in $16 \mathrm{~S}$ samples and 4.5 in ITS samples). The calculated beta diversity showed significant differences $(P=0.001)$ in the composition of the microbiomes of the two groups. All samples of diseased sugar beets $(n=27)$ clustered significantly $(P=0.001)$ different from samples of healthy sugar beets $(n=46)$ (Fig. 1A).

Samples from the healthy sugar beets were further split into two groups, representing high $(n=23)$ and low $(n=23)$ proportions of antagonists (according to Table 1). The threshold for clustering was set to $6 \%$ antagonist incidence. The Shannon indices of the three 
subgroups were compared in order to further assess differences in alpha diversity (Fig. 1B). There was no significant difference between the two healthy groups in the 16S rRNA gene amplicons; however, there was a significant difference between all three groups in the ITS region amplicons.

The core microbiome composition differs between healthy and diseased sugar beets. Bioinformatics analysis of the core microbiomes from healthy and diseased sugar beets showed a clear difference in the community compositions. This was observed with the bacterial as well as the fungal data when comparing healthy and diseased groups (Fig. 2). Proteobacteria (36\%), mostly from the class Alphaproteobacteria (14 to $22 \%$ ), made up the biggest fraction of taxa in both healthy and diseased samples. Bacteroidetes (16 to $20 \%$ ) and Actinobacteria (10 to $14 \%$ ) were also among the predominant phyla in healthy as well as diseased samples. The phylum of Firmicutes, with an average abundance of $2 \%$ in the healthy compared with $37 \%$ in the diseased samples, showed the biggest difference between those two groups. While at the order level Lactobacillales (average abundance: 35\%) and Enterobacteriales $(10 \%)$ were the predominant taxonomic groups in diseased sugar beet roots; healthy samples, on the other hand, where Flavobacteriales (15\%), Rhizobiales (12\%) and Sphingomonadales $(8 \%)$ were the most abundant taxonomic groups, showed a more balanced distribution between all of the taxa.

In the fungal dataset, Ascomycota with an average abundance of $80 \%$ in healthy and $90 \%$ in diseased samples were the main feature fraction of all samples. Basidiomycota (17\% in healthy, $4.5 \%$ in diseased samples), Mortierellomycota (1.5\% in healthy, $0 \%$ in diseased samples), and unassigned phyla (3\% in healthy, $7 \%$ in diseased samples) highlighted the first differences between the two groups. At the class level, Sordariomycetes (53\%), Tremellomycetes (15\%), and Dothideomycetes (12\%) were the most prominent OTUs in healthy samples, while Sordariomycetes (38\%), Saccharomycetes (34\%), and Eurotiomycetes (8\%) were prominent in diseased sugar beets. On the genus level, the distinct change from a healthy to a diseased mycobiome is the most visible. A change in taxonomic groups such as Plectosphaerella (22\%) and Vishniacozyma (12\%) in the healthy beet samples to Candida $(31 \%)$, Fusarium (16\%), and Penicillium (8\%) in the diseased samples was observed. Both healthy groups (high and low antagonism),
A

\section{BACTERIA}

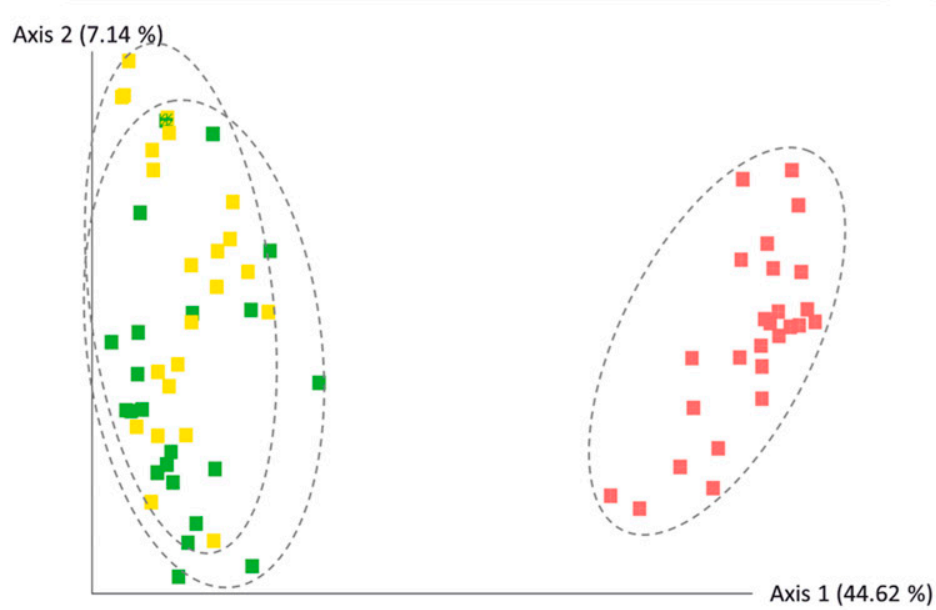

\section{FUNGI}

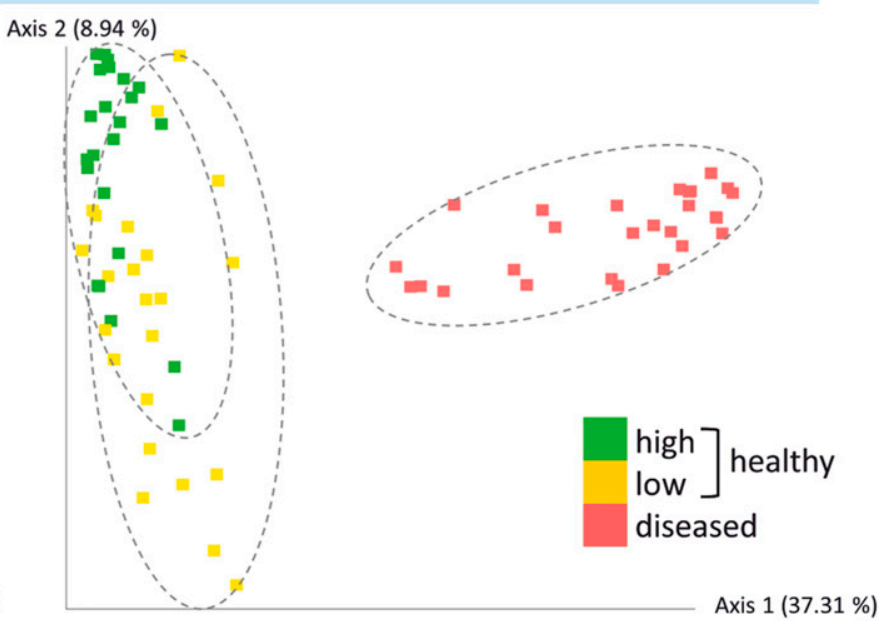

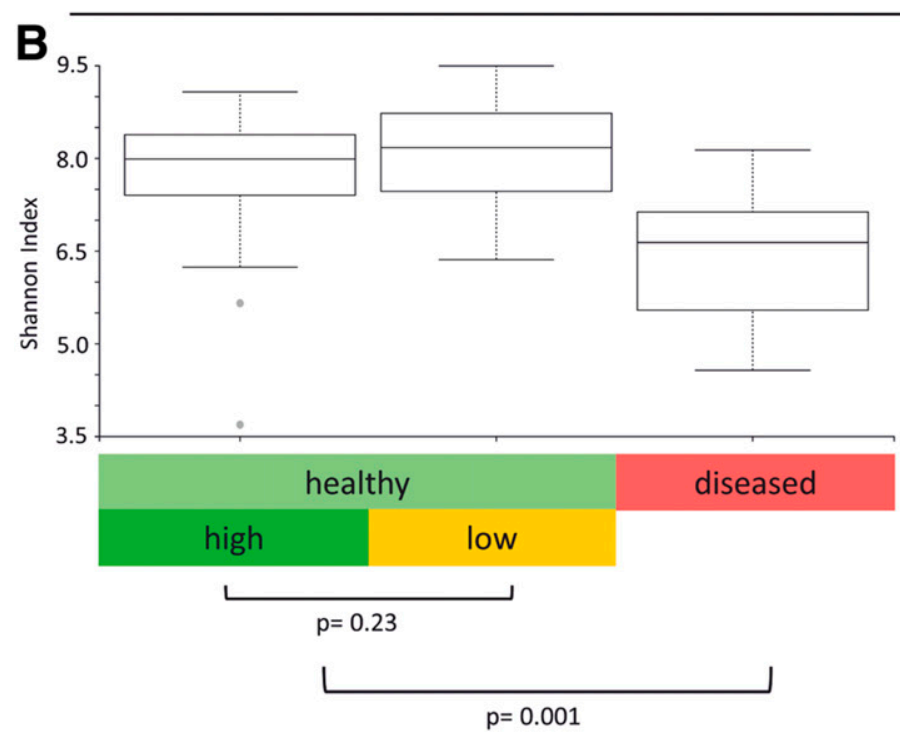

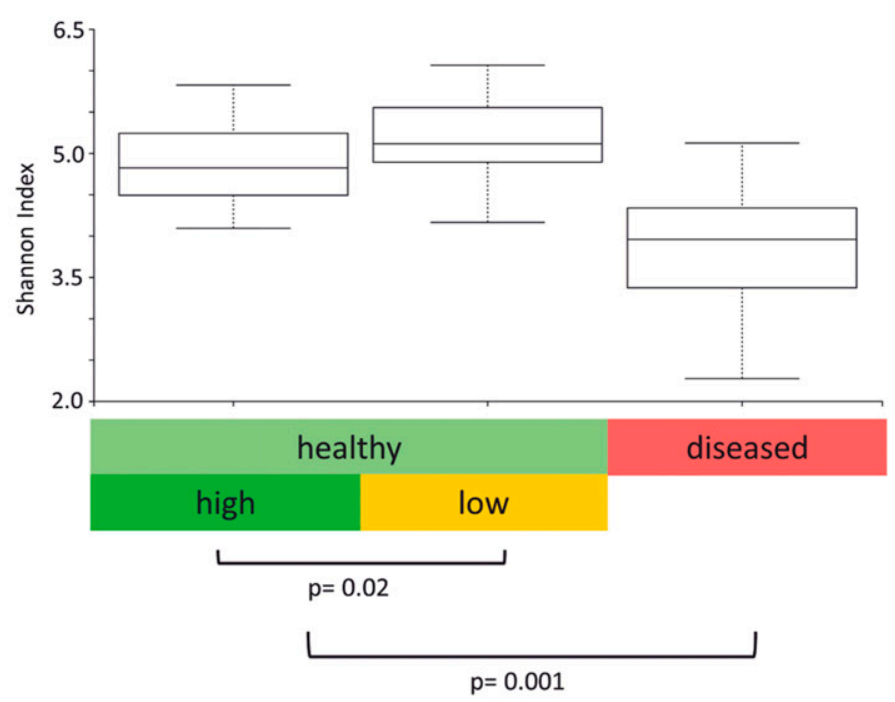

Fig. 1. Microbial diversity of sugar beets grown in fields in Austria and Germany. A, PCoA plots show the bacterial and fungal samples indicated with dots. Significant differences $(P \leq 0.05)$ can be obtained from a total of 46 healthy and 27 diseased samples. Distances shown in the plot are based on the Bray Curtis diversity metrics. B, Shannon indices of healthy (high [ $>6 \%$ antagonists] and low [ $<6 \%$ antagonists]) and diseased sugar beets are shown in boxplots. The significance of the differences between different samples is indicated through $P$ values obtained with pairwise Kruskal-Wallis tests. 
however, were shown to be very similar in the bacteriome. Only the fungal microbiome showed a decrease of Vishniacozyma $(16 \%$ down to $8 \%$ ) as well as Plectosphaerella (25\% down to $20 \%$ ) species from high to low antagonism. To highlight the less evident differences in the fungal microbiome, a network analysis was performed. A lower diversity as well as taxa such as Candida, Fusarium, and Penicillium species had a higher prevalence in the microbiome of diseased sugar beets, whereas a higher total abundance as well as taxa such as Plectosphaerella or Vishniacozyma species were mostly found in both of the healthy groups (Fig. 3). Plectosphaerella ( $-5 \%$ points) and Vishniacozyma ( $-8 \%$ points) species were decreased in low antagonistic samples, while Candida ( $+1.5 \%$ points) as well as most of the shared taxa with the high antagonistic group were increased.

A total of three predominant bacterial and six fungal indicator organisms were identified for healthy and diseased sugar beets. The bacterial order Lactobacillales, as well as the fungal genera Candida, Fusarium, and Penicillium indicate a diseased status reflected by the microbiome. On the other hand, the bacterial order Flavobacteriales and the class Cyanobacteria as well as the fungal genera Plectosphaerella, Vishniacozyma and the class Sordariomycetes reflect a healthy status (Fig. 4).
Taxonomic changes are accompanied by functional specification in the fungal microbiome. The differences on a taxonomic level between the two groups were further verified by analyzing the trophic modes of the found core OTUs (Fig. 5). The analysis revealed a higher abundance of saprotrophic fungi in diseased samples (57\% compared with 20 to $21 \%$ in healthy samples). Interestingly, symbiotrophic fungal taxa almost exclusively occurred in healthy samples (5\% in "high" samples, $8 \%$ in "low" samples compared with $0.3 \%$ in diseased samples). Overall, the fraction of pathotrophic fungi was found to be higher in healthy samples; however, in diseased samples saprotrophic fungi were dominant in the mycobiome.

\section{DISCUSSION}

Microbial diversity decrease is linked to disease incidence. Within the present study, we could show that field-grown healthy and diseased sugar beets harbor a significantly distinct microbiome as well as microbial indicators. Sugar beets derived from different fields in Austria and Germany showed substantial changes in microbial diversity and composition, when spatially close healthy and diseased samples were compared. Diseased plants showed a

\section{A BACTERIA}
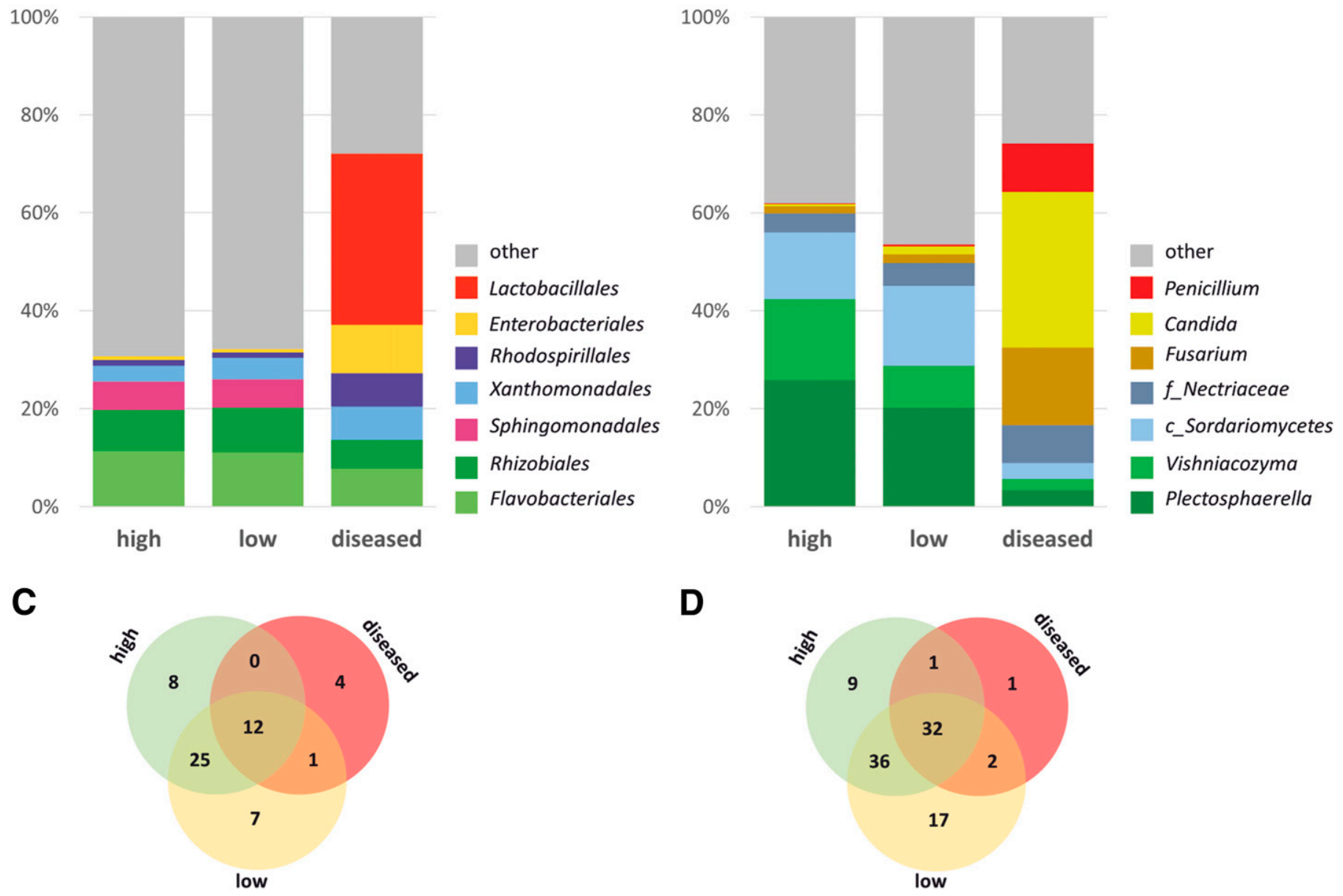

D

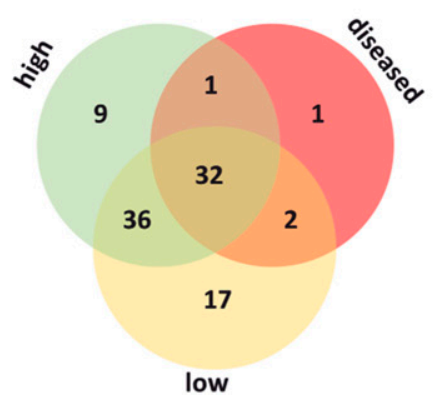

Fig. 2. Relative composition of the bacterial and fungal core microbiome in different sugar beet samples. Healthy sugar beet samples are clustered into "high" and "low" according to their antagonistic potential in Table 1. Bacterial taxa are shown on the left, and fungi are shown on the right. The most abundant $\mathbf{A},(>5 \%)$ bacterial taxa are shown at order level, and $\mathbf{B},(>7 \%)$ fungal taxa at genus level, or when specifically indicated at $f_{-}$, family level and $\mathbf{C}_{-}$, class level. $\mathbf{C}$ and $\mathbf{D}$, Venn diagrams show the shared and unique number of taxa for each sample group. 
significant decrease in microbial diversity. Microbial diversity was previously shown to be an important factor for plant health and suggested as a health indicator (Berg et al. 2017; Yan et al. 2017). Keesing et al. (2010) suggested that reduced microbial diversity is not only an indicator for disease in plants but also in animals and humans. This follows the hypothesis that diverse microbial communities are able to regulate the abundance of pathogenic microbes and prevent the invasion of alien species (van Elsas et al. 2012).

The evaluated antagonistic potential toward fungal pathogens of isolated bacteria from sampled sugar beets displayed a higher frequency of antagonistic bacteria on some fields. In complementary studies, Zachow et al. $(2014,2008)$ already reported the high antagonistic potential of sugar beet-associated bacteria. Especially highly infected sugar beet fields were shown to harbor a higher number of antagonists in their microbiota. However, the differences between high and low antagonistic sugar beet microbiomes were less pronounced. No significant changes in the bacteriome and only small changes in the abundance of specific fungal taxa such as Vishniacozyma (-7\% points) or Plectosphaerella $(-5 \%$ points) were observed. This could be indicative for the importance of those taxa for a healthy microbiome. While the bacterial community was rather similar between the two microbiomes with different antagonistic level, the minor shift in the fungal community could have resulted from the higher proportion of antagonistic bacteria. Due to unspecific interactions with pathogenic and nonpathogenic fungi, antagonistic bacteria within the community of healthy beet roots could be a key factor to avert the prevalence of disease-inducing as well as indicating taxa. This once more highlights the tight interplay between different microbes (bacteria and fungi) in the plant associated community with the plant as already reported in previous studies (Artursson et al. 2005; Berendsen et al. 2012).

Changes in mycobiome functioning in healthy and diseased sugar beets. Predictions of trophic specialization based on the ITS region amplicons, revealed a balanced fungal microbiome in both healthy groups, however, an increased fraction of saprotrophic fungi in diseased samples. Higher proportions of Candida and Penicillium spp. in those samples resulted in this higher abundance of saprotrophic fungi. The high proportion of pathotrophic fungi in both healthy samples is due to the increased abundance of Plectosphaerella sp., which was the most abundant taxonomic group in those samples. Several Plectosphaerella species are associated with root rot in melon (Cucumis melo) (Carlucci et al. 2012). Symbiotrophic fungi only occurred in healthy groups in a higher proportion $(>5 \%)$, due to an increased fraction of the fungal genera Colletotrichum and Mortierella in those samples. Despite the observed severe changes between healthy and diseased samples, only minor changes can be observed between both healthy (high and low

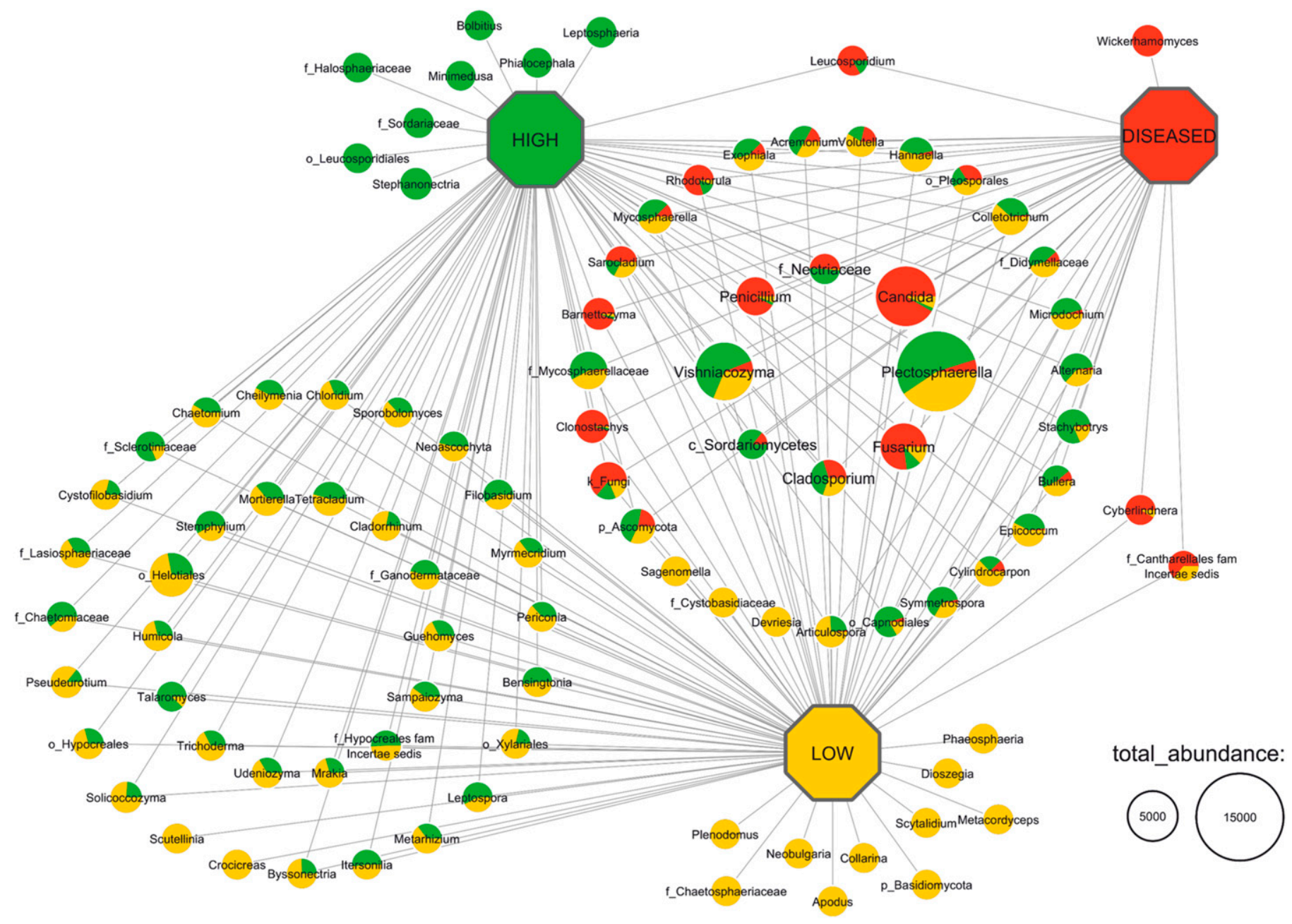

Fig. 3. The shared fungal taxa between high ( $>6 \%$ antagonists), low ( $<6 \%$ antagonists), and diseased groups are shown in an operational taxonomic unit network. Pie charts in the nodes indicate the fraction of the taxa coming from each group. Node size correlates with the total taxa abundance.

The taxonomic level of the features is indicated by $k_{-}$, kingdom; $f_{-}$, family; $c_{-}$, class; or o_, order. 
antagonism) groups. The decrease of the group "pathotrophsaprotroph-symbiotroph" in the samples with low antagonism resulted from the lower abundance of Vishniacozyma in those samples. Additionally, the decrease of Plectosphaerella sp. went along with the decrease of pathotrophic fungi. Overall, the findings suggest a change from a fungal microbiome balanced in functions (both healthy groups) to a more saprotrophic dominated microbiome in diseased samples. The pathotrophic fungi in the healthy samples were replaced by saprotrophic fungi in diseased samples, more involved in degradation processes, as already observed in other studies (Cooke and Rayner 1984). In the samples of low antagonistic potential, this decrease of pathotrophic fungi is already indicated through taxonomic changes.

Indicator taxa can be defined to investigate disease development. The data reported in this study showed a highly pronounced difference between a healthy sugar beet and its infected counterpart. Those differences in the microbiome of sugar beets can be used to define key taxa, which indicate a healthy and a diseased sugar beet microbiome. Some of the taxa indicative for a healthy microbiome were shown to have beneficial effects on plant growth or disease control. Plectosphaerella cucumerina, to which species all of the found Plectosphaerella species belong, is a necrotrophic fungus from the class Sordariomycetes, which was previously described as a potential biological control agent against potato cyst nematodes (Atkins et al. 2003) as well as a potential bioherbicide in a recent study (Bailey et al. 2017). Moreover, beneficial effects on sugar beets growth was previously described (Ying-Wu et al. 2009). Flavobacteria are typical rhizosphere bacteria and known for their

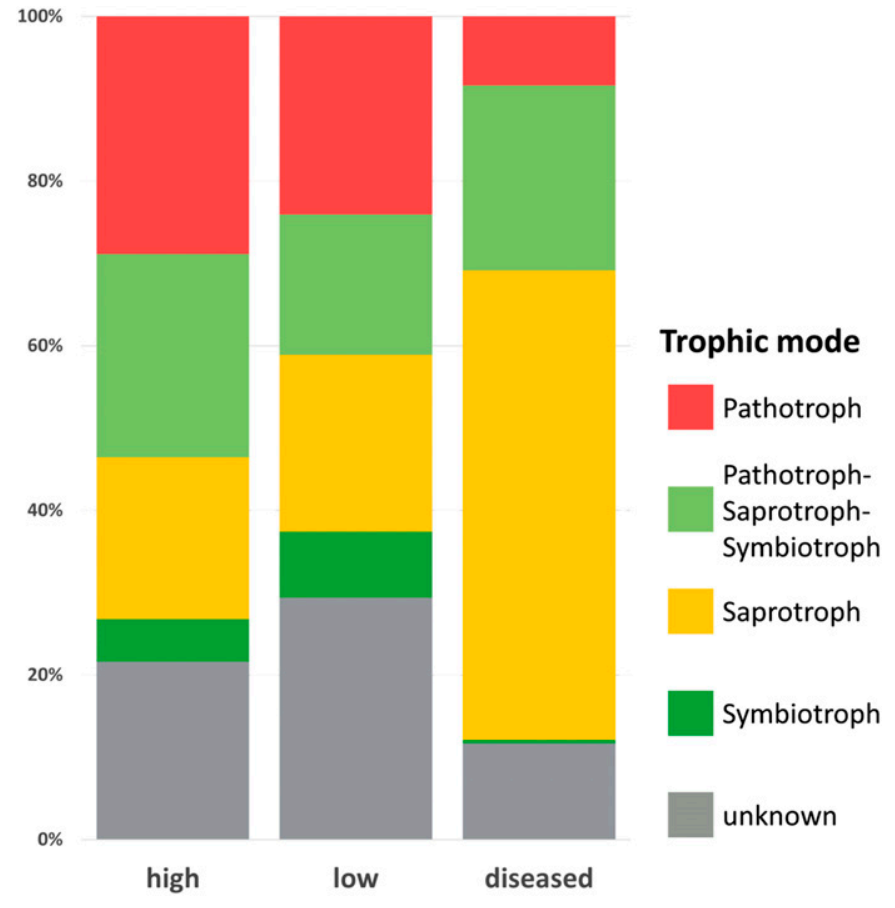

Fig. 5. Relative abundances of fungal operational taxonomic units in the three groups classified by trophic mode. Functions were assigned using the FUNGuild database and the internal transcribed spacer core feature table.

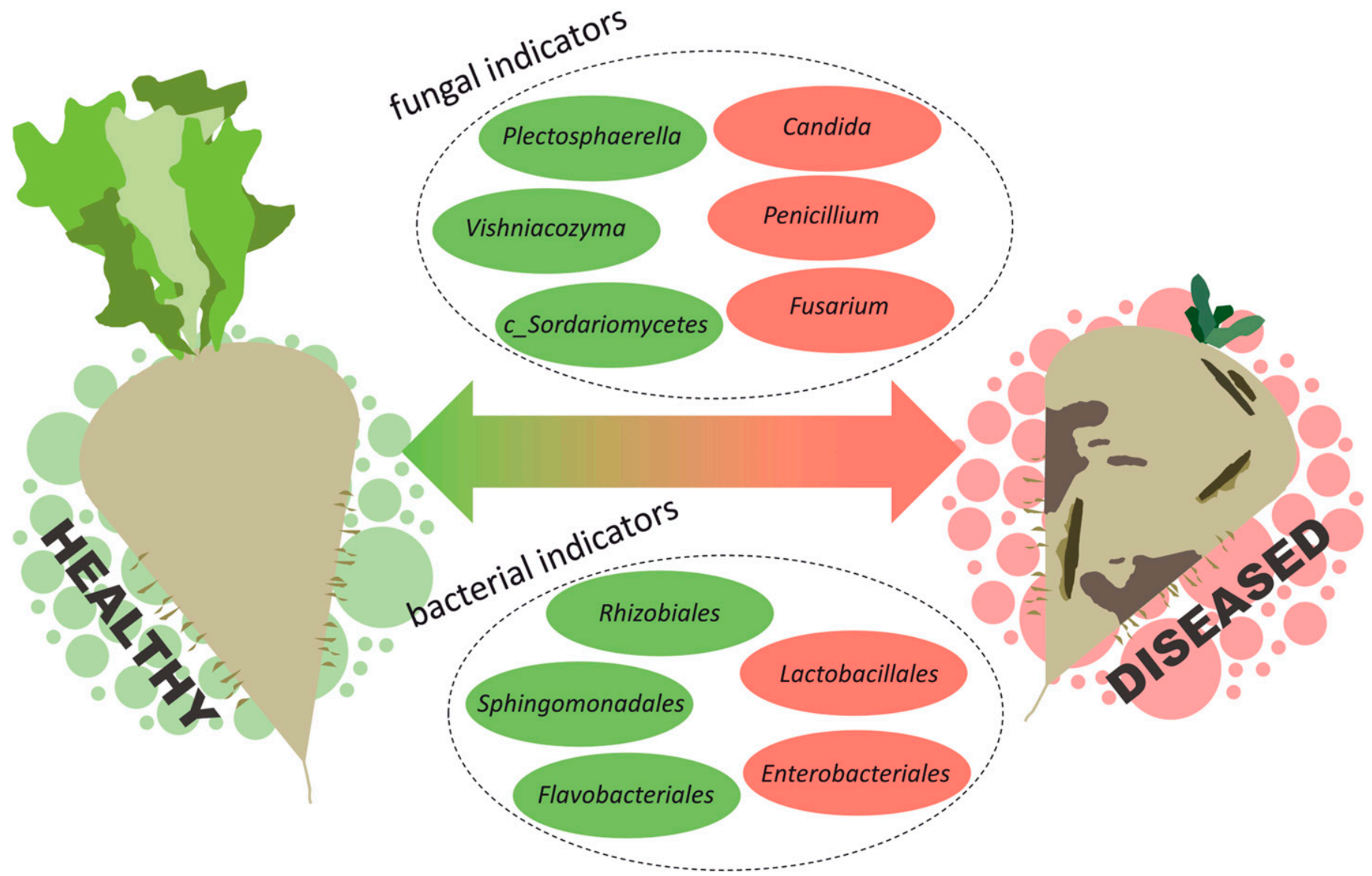

Fig. 4. Identified indicator taxa based on observations of differences in microbiomes of healthy (green) and diseased (red) field-grown sugar beets. Fungal genera (or classes (c_)) are listed on the top, and bacterial orders are listed on the bottom of the illustration. 
root colonization (Bulgarelli et al. 2012). They are currently in discussion for their involvement in plant defense mechanisms (Kolton et al. 2014). Taxa associated with the diseased microbiome such as Fusarium and Penicillium are typically found on sugar beets during storage and are also associated with sugar reduction after harvest (Liebe et al. 2016; Liebe and Varrelmann 2015). Additionally, Lactobacillales, known for the fermentation of sugar in food products, can potentially reduce the sugar content when colonizing sugar beets after the harvest and are therefore unwanted.

Microbial diversity as well as the presence of specific, plantbeneficial microbes is a key factor for plant health. In the present study, potentially beneficial as well as harmful bacterial and fungal taxa were found to interplay in a highly complex microbial community. Changes in the microbial composition could affect the plant's sensibility to different diseases during plant development and indicator species represent a potential early detection system for disease development during growth or storage after harvest. We could show that taxonomic changes were accompanied by changes in the trophic specialization of the mycobiome. Moreover, the antagonistic potential within the bacterial community negatively correlates with the prevalence of saprophytic fungi. This might be indicative for health maintenance by the indigenous microbial community. The overall findings provide the basis for targeted disease control in sugar beet cultivation as well as the development of disease preventing field management.

\section{ACKNOWLEDGMENTS}

We thank A. Heinzel (Graz) and B. Fetz (Graz) for the help with laboratory work and S. Siebauer (Plattling) for help during sampling.

\section{LITERATURE CITED}

Artursson, V., Finlay, R. D., and Jansson, J. K. 2005. Interactions between arbuscular mycorrhizal fungi and bacteria and their potential for stimulating plant growth. Environ. Microbiol. 8:1-10.

Atkins, S. D., Clark, I. M., Sosnowska, D., Hirsch, P. R., and Kerry, B. R. 2003. Detection and quantification of Plectosphaerella cucumerina, a potential biological control agent of potato cyst nematodes, by using conventional PCR, real-time PCR, selective media, and baiting. Appl. Environ. Microbiol. 69:4788-4793.

Bailey, K., Derby, J.-A., Bourdôt, G., Skipp, B., Cripps, M., Hurrell, G., Saville, D., and Noble, A. 2017. Plectosphaerella cucumerina as a bioherbicide for Cirsium arvense: Proof of concept. BioControl 62:693-704.

Bartholomäus, A., Mittler, S., Märländer, B., and Varrelmann, M. 2017. Control of Rhizoctonia solani in sugar beet and effect of fungicide application and plant cultivar on inoculum potential in the soil. Plant Dis. 101:941-947.

Berendsen, R. L., Pieterse, C. M. J., and Bakker, P. A. H. M. 2012. The rhizosphere microbiome and plant health. Trends Plant Sci. 17:478-486.

Berg, G. 2009. Plant-microbe interactions promoting plant growth and health: Perspectives for controlled use of microorganisms in agriculture. Appl. Microbiol. Biotechnol. 84:11-18.

Berg, G., Grube, M., Schloter, M., and Smalla, K. 2014. Unraveling the plant microbiome: Looking back and future perspectives. Front. Microbiol. 5.

Berg, G., Köberl, M., Rybakova, D., Müller, H., Grosch, R., and Smalla, K. 2017. Plant microbial diversity is suggested as the key to future biocontrol and health trends. FEMS Microbiol. Ecol. 93:fix050.

Berg, G., Roskot, N., Steidle, A., Eberl, L., Zock, A., and Smalla, K. 2002. Plantdependent genotypic and phenotypic diversity of antagonistic rhizobacteria isolated from different Verticillium host plants. Appl. Environ. Microbiol. 68: 3328-3338.

Berg, G., Rybakova, D., Grube, M., and Köberl, M. 2016. The plant microbiome explored: Implications for experimental botany. J. Exp. Bot. 67:995-1002.

Berg, G., and Smalla, K. 2009. Plant species and soil type cooperatively shape the structure and function of microbial communities in the rhizosphere. FEMS Microbiol. Ecol. 68:1-13.

Bulgarelli, D., Rott, M., Schlaeppi, K., van Themaat, E. V. L., Ahmadinejad, N., Assenza, F., Rauf, P., Huettel, B., Reinhardt, R., Schmelzer, E., Peplies, J.,
Gloeckner, F. O., Amann, R., Eickhorst, T., and Schulze-Lefert, P. 2012 Revealing structure and assembly cues for Arabidopsis root-inhabiting bacterial microbiota. Nature 488:91-95.

Büttner, G., Pfähler, B., and Märländer, B. 2008. Greenhouse and field techniques for testing sugar beet for resistance to Rhizoctonia root and crown rot. Plant Breed. 123:158-166.

Callahan, B. J., McMurdie, P. J., Rosen, M. J., Han, A. W., Johnson, A. J. A., and Holmes, S. P. 2016. DADA2: High resolution sample inference from Illumina amplicon data. Nat. Methods 13:581-583.

Caporaso, J. G., Kuczynski, J., Stombaugh, J., Bittinger, K., Bushman, F. D., Costello, E. K., Fierer, N., Peña, A. G., Goodrich, J. K., Gordon, J. I., Huttley, G. A., Kelley, S. T., Knights, D., Koenig, J. E., Ley, R. E., Lozupone, C. A., McDonald, D., Muegge, B. D., Pirrung, M., Reeder, J., Sevinsky, J. R., Turnbaugh, P. J., Walters, W. A., Widmann, J., Yatsunenko, T., Zaneveld, J., and Knight, R. 2010. QIIME allows analysis of high-throughput community sequencing data. Nat. Methods 7:335-336.

Carlucci, A., Raimondo, M. L., Santos, J., and Phillips, A. J. L. 2012. Plectosphaerella species associated with root and collar rots of horticultural crops in southern Italy. Persoonia Mol. Phylogeny Evol. Fungi 28:34-48.

Compant, S., Clément, C., and Sessitsch, A. 2010. Plant growth-promoting bacteria in the rhizo- and endosphere of plants: Their role, colonization, mechanisms involved and prospects for utilization. Soil Biol. Biochem. 42: 669-678.

Cooke, R. C., and Rayner, A. D. M. 1984. Ecology of Saprotrophic Fungi. Longman, New York.

Drechsler, C. 1928. The occurrence of Aphanomyces cochlioides n.sp. on sugar beets in the United States. Phytopathology 18:149.

Georgakopoulos, D. G., Fiddaman, P., Leifert, C., and Malathrakis, N. E. 2002. Biological control of cucumber and sugar beet damping-off caused by Pythium ultimum with bacterial and fungal antagonists. J. Appl. Microbiol. 92:1078-1086.

Götze, P., Rücknagel, J., Wensch-Dorendorf, M., Märländer, B., and Christen, O. 2017. Crop rotation effects on yield, technological quality and yield stability of sugar beet after 45 trial years. Eur. J. Agron. 82:50-59.

Keesing, F., Belden, L. K., Daszak, P., Dobson, A., Harvell, C. D., Holt, R. D., Hudson, P., Jolles, A., Jones, K. E., Mitchell, C. E., Myers, S. S., Bogich, T., and Ostfeld, R. S. 2010. Impacts of biodiversity on the emergence and transmission of infectious diseases. Nature 468:647-652.

Kenter, C., Hoffmann, C. M., and Märländer, B. 2006. Effects of weather variables on sugar beet yield development (Beta vulgaris L.). Eur. J. Agron. 24:62-69.

Kiewnick, S., Jacobsen, B. J., Braun-Kiewnick, A., Eckhoff, J. L. A., and Bergman, J. W. 2001. Integrated control of Rhizoctonia crown and root rot of sugar beet with fungicides and antagonistic bacteria. Plant Dis. 85:718-722.

Kõljalg, U., Nilsson, R. H., Abarenkov, K., Tedersoo, L., Taylor, A. F. S., Bahram, M., Bates, S. T., Bruns, T. D., Bengtsson-Palme, J., Callaghan, T. M., Douglas, B., Drenkhan, T., Eberhardt, U., Dueñas, M., Grebenc, T., Griffith, G. W., Hartmann, M., Kirk, P. M., Kohout, P., Larsson, E., Lindahl, B. D., Lücking, R., Martín, M. P., Matheny, P. B., Nguyen, N. H., Niskanen, T., Oja, J., Peay, K. G., Peintner, U., Peterson, M., Põldmaa, K., Saag, L., Saar, I., Schüßler, A., Scott, J. A., Senés, C., Smith, M. E., Suija, A., Taylor, D. L., Telleria, M. T., Weiss, M., and Larsson, K.-H. 2013. Towards a unified paradigm for sequence-based identification of fungi. Mol. Ecol. 22: 5271-5277.

Kolton, M., Frenkel, O., Elad, Y., and Cytryn, E. 2014. Potential role of Flavobacterial gliding-motility and Type IX secretion system complex in root colonization and plant defense. Mol. Plant-Microbe Interact. 27:1005-1013.

Krings, M., Taylor, T.N., Dotzler, N., 2012. Fungal endophytes as a driving force in land plant evolution: Evidence from the fossil record. Pages 5-27 in: Biocomplexity of Plant-Fungal Interactions. D. Southworth, ed. John Wiley $\&$ Sons.

Liebe, S., and Varrelmann, M. 2015. Effect of environment and sugar beet genotype on root rot development and pathogen profile during storage. Phytopathology 106:65-75.

Liebe, S., Wibberg, D., Winkler, A., Pühler, A., Schlüter, A., and Varrelmann, M. 2016. Taxonomic analysis of the microbial community in stored sugar beets using high-throughput sequencing of different marker genes. FEMS Microbiol. Ecol. 92:fiw004.

Lugtenberg, B. J. J., Chin-A-Woeng, T. F. C., and Bloemberg, G. V. 2002. Microbe-plant interactions: principles and mechanisms. Antonie van Leeuwenhoek 81:373-383.

Lundberg, D. S., Yourstone, S., Mieczkowski, P., Jones, C. D., and Dangl, J. L. 2013. Practical innovations for high-throughput amplicon sequencing. Nat. Methods 10:999-1002. 
Maung, T. A., and Gustafson, C. R. 2011. The economic feasibility of sugar beet biofuel production in central North Dakota. Biomass Bioenergy 35: 3737-3747.

Mendes, R., Kruijt, M., de Bruijn, I., Dekkers, E., van der Voort, M., Schneider, J. H. M., Piceno, Y. M., DeSantis, T. Z., Andersen, G. L., Bakker, P. A. H. M., and Raaijmakers, J. M. 2011. Deciphering the rhizosphere microbiome for disease-suppressive bacteria. Science 332:1097-1100.

Osburn, R. M., Schroth, M. N., Hancock, J. G., and Hendson, M. 1989. Dynamics of sugar beet seed colonization by Pythium ultimum and Pseudomonas species: Effects on seed rot and damping-off. Phytopathology 79:709-716.

Pervin, L., and Islam, M. S. 2015. System dynamics approach for modeling of sugar beet yield considering the effects of climatic variables. J. Sci. Food Agric. 95:515-521.

Quast, C., Pruesse, E., Yilmaz, P., Gerken, J., Schweer, T., Yarza, P., Peplies, J., and Glöckner, F. O. 2013. The SILVA ribosomal RNA gene database project: Improved data processing and web-based tools. Nucleic Acids Res.: D590-D596.

Raaijmakers, J. M., Paulitz, T. C., Steinberg, C., Alabouvette, C., and Moënne-Loccoz, Y. 2009. The rhizosphere: A playground and battlefield for soilborne pathogens and beneficial microorganisms. Plant Soil 321: 341-361.

Shannon, P., Markiel, A., Ozier, O., Baliga, N. S., Wang, J. T., Ramage, D., Amin, N., Schwikowski, B., and Ideker, T. 2003. Cytoscape: A software environment for integrated models of biomolecular interaction networks. Genome Res. 13:2498-2504.

Trebbi, D., and McGrath, J. M. 2004. Fluorometric sucrose evaluation for sugar beet. J. Agric. Food Chem. 52:6862-6867. van Elsas, J. D., Chiurazzi, M., Mallon, C. A., Elhottovā, D., Krištůfek, V., and Salles, J. F. 2012. Microbial diversity determines the invasion of soil by a bacterial pathogen. Proc. Natl. Acad. Sci. 109:1159-1164.

Vandenkoornhuyse, P., Quaiser, A., Duhamel, M., Le Van, A., and Dufresne, A. 2015. The importance of the microbiome of the plant holobiont. New Phytol. 206:1196-1206.

Walters, W., Hyde, E. R., Berg-Lyons, D., Ackermann, G., Humphrey, G., Parada, A., Gilbert, J. A., Jansson, J. K., Caporaso, J. G., Fuhrman, J. A., Apprill, A., and Knight, R. 2015. Improved bacterial 16S rRNA gene (V4 and V4-5) and fungal internal transcribed spacer marker gene primers for microbial community surveys. mSystems 1:e00009-15.

Weiland, J., and Koch, G. 2014. Sugarbeet leaf spot disease (Cercospora beticola Sacc.). Mol. Plant Pathol. 5:157-166.

Yan, Y., Kuramae, E. E., de Hollander, M., Klinkhamer, P. G. L., and van Veen, J. A. 2017. Functional traits dominate the diversity-related selection of bacterial communities in the rhizosphere. ISME J. 11:56-66.

Ying-Wu, S., Kai, L., and Chun, L. 2009. Effects of endophytic fungus on sugar content and key enzymes activity in nitrogen and sugar metabolism of sugar beet (Beta vulgaris L.). Acta Agron. Sin. 35:946-951.

Zachow, C., Fatehi, J., Cardinale, M., Tilcher, R., and Berg, G. 2010. Strainspecific colonization pattern of Rhizoctonia antagonists in the root system of sugar beet. FEMS Microbiol. Ecol. 74:124-135.

Zachow, C., Müller, H., Tilcher, R., and Berg, G. 2014. Differences between the rhizosphere microbiome of Beta vulgaris ssp. maritima-ancestor of all beet crops-and modern sugar beets. Front. Microbiol. 5:415.

Zachow, C., Tilcher, R., and Berg, G. 2008. Sugar beet-associated bacterial and fungal communities show a high indigenous antagonistic potential against plant pathogens. Microbiol. Ecol. 55:119-129. 